ORIGINAL ARTICLE

\title{
Echinococcus granulosus sensu lato GENOTYPES IN DOMESTIC LIVESTOCK AND HUMANS IN GOLESTAN PROVINCE, IRAN
}

\author{
Mitra SHARBATKHORI(1,2), Asal TANZIFI(3), Sima ROSTAMI(4), Masoomeh ROSTAMI(2) \& Majid FASIHI HARANDI(5)
}

\begin{abstract}
SUMMARY
Cystic echinococcosis (CE) is a globally parasitic zoonosis caused by larval stages of Echinococcus granulosus. This study investigated E. granulosus genotypes isolated from livestock and humans in the Golestan province, northern Iran, southeast of the Caspian sea, using partial sequencing data of the cytochrome $c$ oxidase subunit 1 (coxl) and NADH dehydrogenase 1 (nadl) mitochondrial genes. Seventy E. granulosus isolates were collected from animals in slaughterhouses: 18 isolates from sheep, 40 from cattle, nine from camels, two from buffaloes and one from a goat, along with four human isolates (formalin-fixed, paraffin-embedded tissues) from CE patients of provincial hospitals. All isolates were successfully analysed by PCR amplification and sequencing. The sequence analysis found four E. granulosus genotypes among the $74 \mathrm{CE}$ isolates: G1 (78.3\%), G2 (2.7\%), G3 (15\%) and G6 (4\%). The G1-G3 complex genotype was found in all of the sheep, goat, cattle and buffalo isolates. Among the nine camel isolates, the frequency of G1-G3 and G6 genotypes were 66.7\% and 33.3\%, respectively. All four human CE isolates belonged to E. granulosus sensu stricto. This study reports the first occurrence of the G2 genotype in cattle from Iran and confirms the previously reported G3 genotype in camels in the same country.
\end{abstract}

KEYWORDS: Echinococcus granulosus; Genotyping; coxl; nad1; Iran.

\section{INTRODUCTION}

The larval stage (metacestode) of Echinococcus granulosus, the causative agent of cystic echinococcosis (CE), is the source of a globally distributed zoonotic parasitic disease that causes major medical, veterinary and economic losses in endemic countries, including $\operatorname{Iran}^{1,2}$.

The adult stage of the cestode resides in the small intestine of carnivores, being the domestic and wild canids, the definitive hosts. The intermediate host that harbours metacestodes (hydatid cysts) in liver, lungs and other organs can be one of the numerous species of domestic and wild ungulates, including sheep, goats, cattle, buffalos, camels. Humans may be infected through the accidental intake of parasite eggs in contaminated water or vegetables, or by direct contact with $\operatorname{dogs}^{3}$. CE imposes a considerable economic impact in $\operatorname{Iran}^{4}$. A number of studies have estimated the prevalence of CE in Iranian livestock to be between $5.1 \%$ and $74.4 \%$ in sheep; $3.5 \%$ and $38.3 \%$ in cattle; $2 \%$ and $20 \%$ in goats; $11.9 \%$ and $70 \%$ in buffalos; and between $25.7 \%$ and $59.3 \%$ in camels $^{5,6}$. Human cases of CE are widespread in Iran and are routinely reported from medical centres and hospitals across the country, including approximately $1 \%$ of all surgical cases ${ }^{6,7}$.
In the past 50 years, significant phenotypic and genetic variation has been revealed among $E$. granulosus isolates from different intermediate host species in several geographical areas. This led to the establishment of new species and genotypes. The understanding the E. granulosus species and genotypes has had a significant impact on the epidemiology and control strategies for the disease, as well as for future vaccine and drug design ${ }^{8,9}$. Based mainly on the E. granulosus mitochondrial DNA-based studies, it has been shown that E. granulosus comprises 10 genotypes (G1-G10), which have been characterized as distinct species, comprising E. granulosus sensu stricto (G1, G2 and G3); E. equinus (G4); E. ortleppi (G5); and the controversial group formed by G6-G10 species that according to some authors should be regarded as one species, and to others such as the three species namely E. canadensis, E. borealis and E. intermedius. The validity of the G9 genotype is not clear ${ }^{9-14}$. Recently, the lion strain has been proposed as another new species and E. felidis was settled as a sister taxon of E. granulosus sensu stricto ${ }^{15}$.

Several molecular studies performed in Iran have shown the occurrence of E. granulosus sensu stricto (G1-G3) and E. canadensis $(\mathrm{G} 6)^{16-22}$. Due to the lack of more accurate data from this region, the present study has investigated the population genetic pattern of 


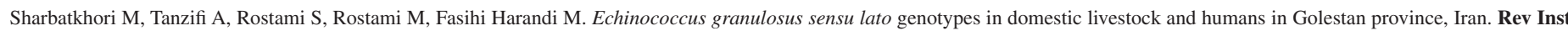
Med Trop Sao Paulo. 2016;58:38.

E. granulosus isolated from livestock and humans by sequencing and the phylogenetic analysis of cytochrome $c$ oxidase subunit 1 (coxl) and NADH dehydrogenase 1 (nad1) mitochondrial genes.

\section{MATERIALS AND METHODS}

\section{Collection of samples}

The present cross-sectional study was performed from April 2011 to July 2012. Hydatid cysts of liver and lung tissues were collected from sheep, goats, cattle, buffalos and camels, in different slaughterhouses, in Golestan province of northern Iran, southeast of the Caspian sea (Table 1). Cysts that did not contain parasites or calcified cysts were excluded from the study. Molecular techniques were conducted on isolates using clean cyst fluid samples and some whitish germinal layer. Additionally, formalin-fixed paraffin-embedded tissues (FFPT) from patients with histologically confirmed hydatid cysts coming from a private hospital of Gorgan were also evaluated in this study (Table 1). Protoscoleces from individual cysts were aspirated and washed three times with normal saline and preserved at $-20{ }^{\circ} \mathrm{C}$ until used for the molecular analysis.

\section{DNA Extraction}

Isolates underwent four freeze and thaw cycles in liquid nitrogen alternated with a passage in a water bath at $95^{\circ} \mathrm{C}$. Samples were then suspended in $200 \mu \mathrm{L}$ of tissue lysis buffer and $80 \mu \mathrm{L}$ of proteinase $\mathrm{K}$ and incubated at $56{ }^{\circ} \mathrm{C}$ overnight ${ }^{23}$. Subsequently, genomic DNA was isolated from the homogenised suspension using a High Pure PCR Template Preparation Kit (Roche, Mannheim, Germany) according to the manufacturer's recommended protocol.

Extracting DNA from FFPE tissues of human CE was performed using a QIAamp DNA FFPE Tissue Kit (Qiagen, Hilden, Germany) according to the manufacturer's instructions.

A spectrophotometer (NanoDrop ${ }^{\circledR}$ ND-1000, Thermo Scientific, Massachusetts, USA) was used to ensure the quality of DNA extraction. The genomic DNA was kept at $-20^{\circ} \mathrm{C}$ until amplification.

Individual genomic DNA samples were analysed using amplification of two mitochondrial DNA fragments within coxl and nadl genes, separately. JB3 (TTTTTTGGGCATCCTGAGGTTTAT) and JB4.5 (TAAAGAAAGAACATAATGAAAAT G) sequences were used as cox 1 forward and reverse primers, and MS1 (AGATTCGTAAGGGGCCTAATA) and MS2 (ACCACTAACTAATTCACTTTC) sequences were used as nadl forward and reverse primers, respectively ${ }^{18}$. PCR was carried out in a final volume of $50 \mu \mathrm{L}$, including $4 \mu \mathrm{L}(50-100 \mathrm{ng})$ of genomic DNA,
$3.5 \mathrm{mM} \mathrm{MgCl}_{2}, 250 \mu \mathrm{M}$ of dNTPs, $25 \mathrm{pmol}$ of each primer and $2 \mathrm{U}$ of Taq polymerase, under the following conditions: 35 cycles of $94^{\circ} \mathrm{C}$ for $30 \mathrm{~s}$, $50{ }^{\circ} \mathrm{C}$ for $45 \mathrm{~s}, 72{ }^{\circ} \mathrm{C}$ for $35 \mathrm{~s}$, followed by a final extension of $72{ }^{\circ} \mathrm{C}$ for $10 \mathrm{~min}$ Negative (no added DNA) and positive controls were included in each PCR experiment. PCR products were analysed by electrophoresis in ethidium bromide-stained $1 \%$ agarose gels prepared in TBE buffer (65 mM Tris-HCl, $22.5 \mathrm{mM}$ boric acid, $1.25 \mathrm{mM}$ EDTA, $\mathrm{pH}$ 9). The gels were visualized using an UV transilluminator (UVitec, Cambridge, UK).

\section{DNA sequencing and phylogenetic analysis}

A panel of 74 PCR amplicons for each coxl and nadl gene was purified and subjected to sequencing in two directions, using the same forward and reverse PCR primers.

The electropherogram of each sequence was visually checked and the sequences were compared to each other and with reference sequences using the BioEdit ${ }^{24}$ and the BLAST softwares available at http://www. ncbi.nlm.nih.gov/. The representative sequences for both coxl and nadl genes were submitted to GenBank.

Three separate phylogenetic analyses of sequencing data were conducted (i) using: pcox 1 data for sequences determined in the present study only, and pcox 1 data for $T$. saginata as the outgroup; (ii) pnad1 data for sequences determined in the present study only, and pnad1 data for $T$. saginata as the outgroup; (iii) concatenated pcox $1+$ pnad 1 data representing all genetic variations detected in the present study, previously described E. granulosus genotypes (G1-G10), Echinococcus species along with $T$. saginata as the outgroup. The character-based Bayesian inference method (BI) was used for the analyses. BI was executed using the software MrBayes v.3.1.2 available at http://mrbayes. csit.fsu.edu/index.php. Posterior probabilities (pp) were designed for 2,000,000 generations (ngen: 2,000,000; burnin: 20000 ) by means of the Monte Carlo Markov Chain method and four simultaneous tree-building chains (nchains:4), with each $100^{\text {th }}$ tree saved (samplefreq:100). The evolutionary distance was determined using the General Time Reversible evolutionary model (nset: 6), allowing for a gamma-shaped variation in mutation rates between codons (rates: g). The TreeviewXv.0.5.0 program $^{25}$ was used to indicate the consequence tree.

\section{RESULTS}

Seventy-four CE isolate fragments of approximately $450 \mathrm{bp}$ and 400 bp long were successfully amplified within coxl and nadl genes, respectively. The obtained consensus sequences of coxl and nadl genes were $366 \mathrm{bp}$ and $378 \mathrm{bp}$, respectively. Fifty-eight (78.3\%), 2 (2.7\%), $11(15 \%)$ and $3(4 \%)$ isolates belonged to the G1, G2, G3 and G6

Table 1

Echinococcus granulosus genotypes in different hosts identified by mitochondrial coxl and nad1 sequence analysis in Golestan province, northern Iran

\begin{tabular}{|c|c|c|c|c|c|c|c|}
\hline $\begin{array}{l}\text { Host (No. of } \\
\text { isolates) }\end{array}$ & Sheep (18) & Goat (1) & Cattle (40) & Buffalo (2) & Camel (9) & Human (4) & Total (74) \\
\hline $\begin{array}{l}\text { Genotypes, No. } \\
(\%)\end{array}$ & $\mathrm{G} 1,18(100)$ & G1, 1 (100) & $\begin{array}{c}\mathrm{G} 1,29(72.5) \\
\mathrm{G} 2,2(5) \\
\mathrm{G} 3,9(22.5)\end{array}$ & G1, 2 (100) & $\begin{array}{l}\text { G1, } 4(44.5) \\
\text { G3 } 2(22.5) \\
\text { G6 } 3(33.3)\end{array}$ & G1, 4 (100) & $\begin{array}{c}\mathrm{G} 1,58(78.3) \\
\mathrm{G} 2,2(2.7) \\
\mathrm{G} 3,11(15) \\
\mathrm{G} 6,3(4)\end{array}$ \\
\hline
\end{tabular}




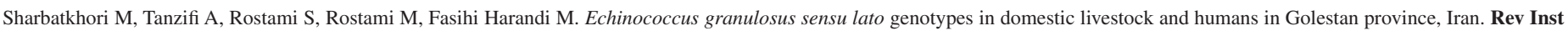
Med Trop Sao Paulo. 2016;58:38.

genotypes, respectively. All four human CE isolates belonged to the G1 genotype (Table 1). The sequence alignments of the isolates displayed eight characteristic profiles in coxl sequences and 5 characteristic profiles in nadl sequences. Sequence profiles for coxl (designated as Golc1-8) and nad1 (designated as Goln1-5) were submitted to GenBank, accession numbers KM513626- KM513633 and KM513634- KM513638, respectively. As some E. granulosus sequences were the same in different hosts, the equal sequence profile in different hosts was named as subnumbers and submitted to GenBank with the related accession numbers KT074941- KT074949 and KT074936- KT074940 for coxl and nadl genes, respectively. For example Golc6 (AN: KM513631), and Golc61 (AN: KT074949), have the same coxl sequence in cattle and camel hosts, respectively (Table 2).

Separate phylogenetic analyses of pcox 1 and pnad 1 data sets were conducted, and all the combinations of coxl and nadl sequence types, representing all the 74 isolates in the present study were determined. These analyses revealed a concordance between the genotypic classification of pcox 1 and pnad1, inferring the utility of combined pcox 1 and pnad 1 data to access the haplotypic variation among E. granulosus. Hence, each pair of pcox1 and pnad1 sequence types (e.g. Golc1- Golc8 and Goln1- Goln5) was used to define the "working" haplotypes (see Table 2 and Fig. 1). In all the cases, concatenated reference sequences represented the same isolate (i.e. Golc1 and Goln 3 sequences were derived from the same isolate representing the haplotype $2(\mathrm{H} 2)$ in the Table2). A data set representing the concatenated pcox $1+$ pnad 1 sequences for all the 15 haplotypes (H1H15) detected in this study was employed, along with key reference data (comprising concatenated pcox $1+$ pnad 1 sequences from previous studies representing all the recognized Echinococcus species and E. granulosus "genotypes", with T. saginata as the outgroup; see Table 2 and Fig. 1).

Phylogenetic analyses of concatenated data, for the haplotypes $1-15$, were performed by using BI, including representative sequence data for all the recognized species of Echinococcus and genotypes of $E$. granulosus, as well as T. saginata as an outgroup (Table 2 and Fig. 1). A consensus tree has been built and is shown in Figure 1.

Most of the isolates (78.3\%) were identified as G1 and were clustered in the G1 reference genotype (accession nos: cox1, U50464; nad1, AJ237632). Isolates that were identified as G2 (2.7\%) were clustered in the G2 reference sequences (accession nos: cox1, M64662; nad1. AJ237633). Isolates identified as G3 (14.86\%) clustered in the G3 reference sequences (accession nos: cox1, M64663; nad1. AJ237634) and isolates identified as G6 (13.1\%) were clustered in the G6 reference sequences (accession nos: cox1, M84666; nad1, AJ237637) (Fig.1).

$\mathrm{H} 1-\mathrm{H} 9$ represents the $\mathrm{G} 1$ genotype, $\mathrm{H} 10$ belongs to the $\mathrm{G} 2$ genotype, H11-H14 represents the G3 genotype, and H15 belongs to the G6 genotype. A consensus tree based on the phylogenetic analyses of concatenated coxl and nadl sequences revealed two distinct clusters. One cluster contained a G1-G3 complex $(\mathrm{pp}=1.00)$ and the other cluster contained the G6-G10 complex (pp = 1.00). Fourteen haplotypes (H1H14) were found in the G1-G3 cluster, and one haplotype was placed in the G6-G10 complex, the E. canadensis (Fig. 1).

\section{DISCUSSION}

The results of this study showed that the G1 genotype (E. granulosus sensu stricto) was the most prevalent identified genotype among the 74 $\mathrm{CE}$ isolates from the Golestan province, northern Iran. The G1 genotype was identified in all of the sheep, goat, buffalo and human isolates. Furthermore, $72.5 \%$ of the cattle and approximately half of the camel $(44.44 \%)$ isolates also belonged to the G1 genotype. Two (5\%) and nine (22.5\%) of the cattle isolates had the G2 and G3 genotype, respectively. Also, two (22.2\%) and three (33.3\%) camel isolates showed the G3 and G6 genotypes, respectively.

A recent study performed in this region using the ITS1-RFLP method, has reported the G1 genotype in all the human, sheep and cattle isolates and both, G1 and G6 genotypes, in camel isolates ${ }^{31}$. However, the G1-G3 genotypes cannot be differentiated by the ITS1-RFLP. In another study, all the five cattle and 10 sheep isolates from the Golestan province had the G1 genotype ${ }^{18}$. The finding of the G1 genotype as the most prevalent one suggests that the sheep-dog cycle is dominant in CE from the Golestan province. G1 is the most frequent genotype found in humans and livestock throughout the world ${ }^{32,33}$; however, in some north African countries, including Mauritania and Sudan, G6 is the most common genotype in sheep, cattle, camels and humans ${ }^{34,35}$.

Although the E. granulosus G2 genotype was primarily introduced as a Tasmanian sheep strain, it was later found in other hosts, including goats, cattle, buffalos, camels and humans, from different countries. In Iran, this genotype has been previously reported and dogs are the definitive hosts. To the best of our knowledge, the present study reports the first occurrence of E. granulosus G2 genotype in intermediate hosts in this country.

The E. granulosus G3 genotype has been previously reported in humans, sheep, goats, cattle and camels in different countries, including $\operatorname{Iran}^{20,21,36-42}$. The present study found this genotype in nine of 40 cattle $(22.5 \%)$ and two of nine camels $(22.2 \%)$. However, no sheep, goat, buffalo, or human isolates harboured the G3 genotype in the present study.

Most of the human CE isolates from Iran have been reported as belonging to the G1 genotype. This is consistent with the findings of the present study, as all four human FFPE tissues had the G1 genotype. In a study from the Isfahan province of central Iran, using PCRRFLP, all 30 human CE isolates were reported as belonging to the G1 genotype $^{43}$. Another study, using SSCP coupled to partial coxl and nad1 sequencing, found that all 23 human CE originally from central Iran had the G1 genotype ${ }^{18}$. A study in the Ardabil province of north western Iran reported seven and two human $\mathrm{CE}$ isolates belonging to the G1 and G3 genotypes, respectively ${ }^{21}$. Harandi et al., using a PCR-RFLP method, reported 33 and three human $\mathrm{CE}$ isolates as belonging to the G1 and G6 genotypes, respectively ${ }^{16}$. The only human CE isolate from the Kerman province of south western Iran showed a G6 genotype ${ }^{20}$. A recent study reported the G6 genotype in all eight FFPE tissues from cerebral Echinococcus cysts in patients from a Tehran hospital. The authors also claimed that the G6 genotype has a higher affinity for the human brain than the G1 genotype ${ }^{44}$. In a study on 125 human isolates conducted by Rostami et al. (2015), G1 and G6 genotypes were shown to be present in 54.4 and $40.8 \%$ of the isolates, respectively. The G6 genotype is especially prevalent in south-eastern parts of the Iran where humans were slightly more infected by camel strains (G6) than G1 strains ( 45.8 vs. $41.7 \%$ ). These data show that humans are quite susceptible to infections by the G6 genotype (E. canadensis), 


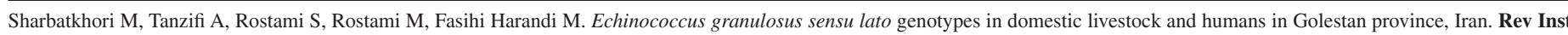
Med Trop Sao Paulo. 2016;58:38.

Table 2

E. granulosus haplotypes from Golestan Province, Iran and reference of sequences used for concatenation (coxl+ nad1) and subsequent phylogenetic analyses (see Fig. 1)

\begin{tabular}{|c|c|c|c|c|}
\hline $\begin{array}{l}\text { E. granulosus sensu lato } \\
\text { haplotypes from Golestan }\end{array}$ & Host & $\begin{array}{c}\text { Profile } \operatorname{coxl} \text { (Accession } \\
\text { number) }\end{array}$ & $\begin{array}{c}\text { Profile } \text { nadl } \\
\text { (Accession number) }\end{array}$ & Reference \\
\hline $\mathrm{H} 1$ & $\begin{array}{l}\text { Human } \\
\text { sheep } \\
\text { cattle }\end{array}$ & $\begin{array}{c}\text { Golc1(KM513626) } \\
\text { Golc1-1( KT074941) } \\
\text { Goc1-2( KT074942) }\end{array}$ & $\begin{array}{c}\text { Goln1(KM513634) } \\
\text { Goln1-1(KT074936) } \\
\text { Goln1-3(KT074938) }\end{array}$ & This study \\
\hline $\mathrm{H} 2$ & Human & Golc1(KM513626) & Goln3(KM513636) & This study \\
\hline $\mathrm{H} 3$ & $\begin{array}{l}\text { Sheep } \\
\text { cattle } \\
\text { camel }\end{array}$ & $\begin{array}{l}\text { Golc1-1(KT074941) } \\
\text { Golc1-2( KT074942) } \\
\text { Golc1-3( KT074943) }\end{array}$ & $\begin{array}{c}\text { Goln4(KM513637) } \\
\text { Goln4-1(KT074939) } \\
\text { Goln4-2(KT074940) }\end{array}$ & This study \\
\hline $\mathrm{H} 4$ & $\begin{array}{l}\text { Human } \\
\text { sheep } \\
\text { cattle }\end{array}$ & $\begin{array}{c}\text { Golc2(KM513627) } \\
\text { Golc2-1(KT074944) } \\
\text { Golc2-2(KT074945) }\end{array}$ & $\begin{array}{c}\text { Goln1(KM513634) } \\
\text { Goln1-1(KT074936) } \\
\text { Goln1-3(KT074938) }\end{array}$ & This study \\
\hline $\mathrm{H} 5$ & Cattle & Golc2-2(KT074945) & Goln2(KM513635) & This study \\
\hline H6 & $\begin{array}{l}\text { Cattle } \\
\text { camel }\end{array}$ & $\begin{array}{l}\text { Golc2-2(KT074945) } \\
\text { Golc2-3(KT074946) }\end{array}$ & $\begin{array}{l}\text { Goln4-1(KT074939) } \\
\text { Goln4-2(KT074940) }\end{array}$ & This study \\
\hline H7 & $\begin{array}{l}\text { Cattle } \\
\text { camel }\end{array}$ & $\begin{array}{c}\text { Golc3(KM513628) } \\
\text { Golc3-1(KT074947) }\end{array}$ & $\begin{array}{l}\text { Goln4-1(KT074939) } \\
\text { Goln4-2(KT074940) }\end{array}$ & This study \\
\hline $\mathrm{H} 8$ & Goat & Golc4(KM513629) & Goln1-2(KT074937) & This study \\
\hline H9 & Cattle & Golc4-1(KT074948) & Goln4-1(KT074939) & This study \\
\hline H10 & Cattle & Golc5(KM513630) & Goln4-1(KT074939) & This study \\
\hline $\mathrm{H} 11$ & Cattle & Golc6(KM513631) & Goln1-3(KT074938) & This study \\
\hline H12 & $\begin{array}{l}\text { Cattle } \\
\text { camel }\end{array}$ & $\begin{array}{c}\text { Golc6(KM513631) } \\
\text { Golc6-1(KT074949) }\end{array}$ & $\begin{array}{l}\text { Goln4-1(KT074939) } \\
\text { Goln4-2(KT074940) }\end{array}$ & This study \\
\hline $\mathrm{H} 13$ & Cattle & Golc7(KM513632) & Goln1-3(KT074938) & This study \\
\hline H14 & Cattle & Golc7(KM513632) & Goln4-1(KT074939) & This study \\
\hline H15 & Camel & Golc8(KM513633) & Goln5(KM513638) & This study \\
\hline
\end{tabular}

\section{E. granulosus sensu lato}

\begin{tabular}{|c|c|c|c|c|}
\hline G1 & Sheep & M84661 & AJ237632 & 26,27 \\
\hline $\mathrm{G} 2$ & Sheep & M84662 & AJ 237633 & 26,27 \\
\hline G3 & Buffalo & M84663 & AJ237634 & 26,27 \\
\hline G4 & Horse & M84664 & AJ237635 & 26,27 \\
\hline G5 & Cattle & M84665 & AJ237636 & 26,27 \\
\hline G6 & Camel & M84666 & AJ237637 & 26,27 \\
\hline G7 & Pig & M84667 & AJ237638 & 26,27 \\
\hline G8 & Moose & AB235848 & AB235848 & 10 \\
\hline G10 & Reindeer & AF525457 & AF525297 & 28 \\
\hline E. felidis & Lion & EF558356 & EF558357 & 15 \\
\hline E. multilocularis1 & Human & M84668 & AJ237639 & 26,27 \\
\hline E. multilocularis 2 & Rodent & M84669 & AJ237640 & 26,27 \\
\hline E. shiquiqus & Pika & AB208064 & AB208064 & 10 \\
\hline E. vogeli & Rodent & M84670 & AJ237641 & 26,27 \\
\hline E. oligarthra & Rodent & M84671 & AJ237642 & 26,27 \\
\hline \multicolumn{5}{|l|}{ Outgroup } \\
\hline Taenia saginata & Cattle & Not available & AJ239106 & 29,30 \\
\hline
\end{tabular}




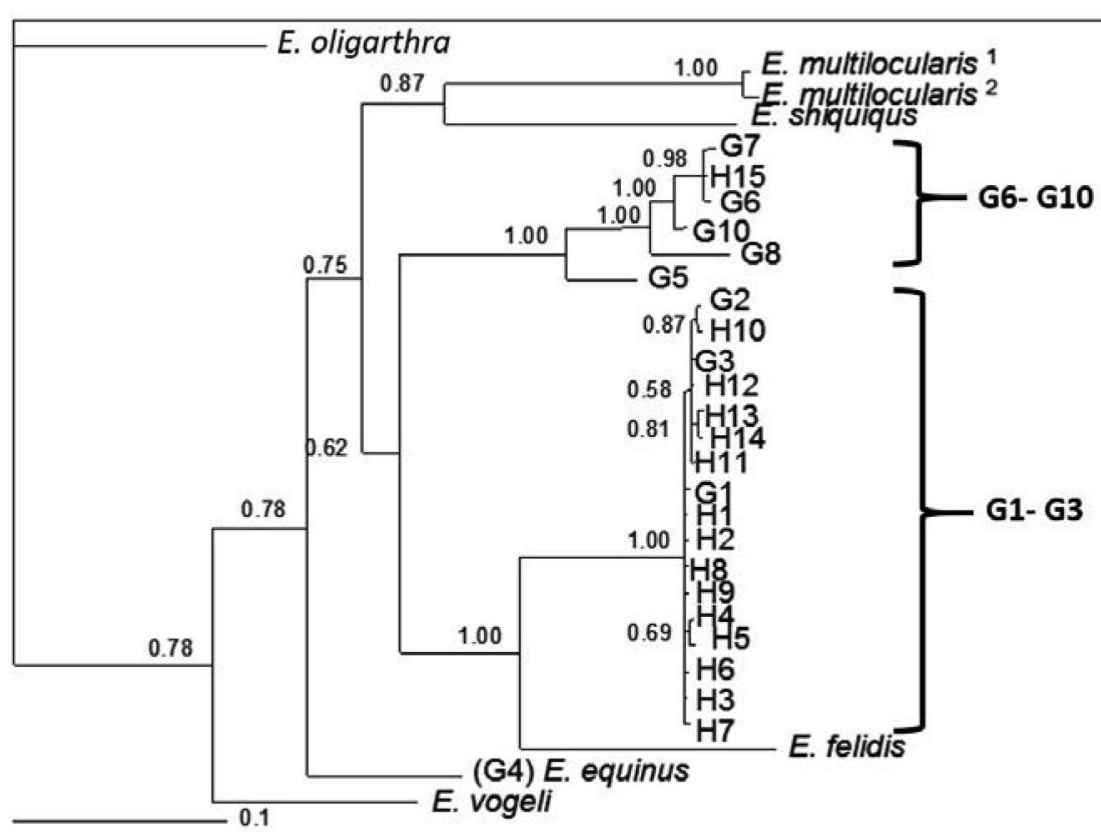

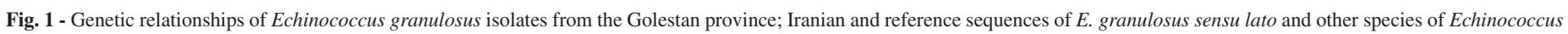

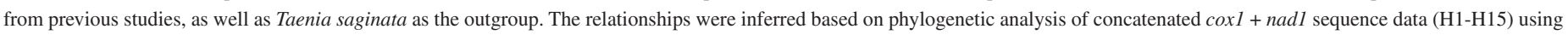

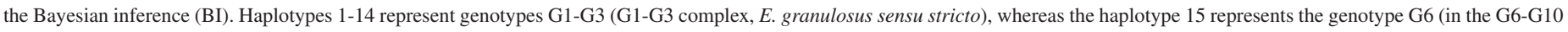
complex, E. canadensis). The accession numbers and sources of sequences are shown in Table 2. Nodal support is given as a pp value.

and also that there is an active camel-dog cycle in many parts of the country with camel and sheep as potential intermediate hosts. The results of the present study indicate the interaction of the camel-dog and the sheep-dog cycles in this Iranian region ${ }^{45}$. In the present study, two of nine $(22.2 \%)$ camel isolates had the G6 genotype. This finding is almost entirely in accordance with a previous study conducted on 19 camel isolates from central Iran that found the G6 genotype in 31.6\% of isolates, with most of the isolates belonging to E. granulosus sensu stricto $(68.4 \%)^{17}$. Furthermore, the low frequency of the G6 genotype in this study may be the result of low breeding and slaughtering of camels in this region.

In the present study, most isolates designated as haplotypes 1 to 14 $(\mathrm{H} 1-\mathrm{H} 14)$, formed a strongly supported clade $(\mathrm{pp}=1.00)$ together with reference sequences representing E. granulosus G1-G3 genotypes (E. granulosus sensu stricto), and the exclusion of E. felidis ( $\mathrm{pp}=1.00)$. $\mathrm{H} 15$ as the only haplotype belonging to the G6 genotype was clustered in the E. granulosus G6-G10 genotypes (known as the E. canadensis G6 genotype) with a maximal statistical support ( $\mathrm{pp}=1.00)$; a strong support was also placed in a smaller cluster in the G6 and G7 genotypes $(\mathrm{pp}=0.98)$.

There are still controversies on the nature of E. canadensis (G6, G7, G8 and G10). The G7 (pig strain) is predominantly found in Europe while the G6 genotype has been found in central Asia, the middle east/ north Africa and South America with a very distinct epidemiological and biological context in comparison with G8 and G10 genotypes. According to Lymbery et al. (2015), G6 and G7 are not believed to be sympatric in most parts of the globe and the nomenclature of G6-G10 genotypes warrants more precise explanation. The division of Echinococcus granulosus sensu lato into G-numbers is a relic of the 1990s and should be reconsidered ${ }^{14,46}$. This is especially true for the micro-variants G1-3 and G6/7, whose biological relevance are largely questionable.

The present study found that the predominant genotype is G1 (78.4\%), as in other areas of the country, and describes the first report of the G2 genotype identified in cattle hosts. Also, this study confirms previous reports of the $\mathrm{G} 3$ genotype in camels and cattle species in the country. As humans can be infected with G2 and G3 genotypes, the epidemiological implication of cattle and camels in maintaining the transmission cycle of different E. granulosus genotypes warrants more attention.

\section{ACKNOWLEDGMENTS}

The authors would like to thank all the veterinary staff of different slaughterhouses that helped the collection of samples for this study. This work was performed as part of a MSc. thesis carried out by A.T. and was equally financially supported by the Vice-Chancellor for Research of Kerman University of Medical Sciences, grant No. 90-435; and the ViceChancellor for Research of Golestan University of Medical Sciences, grant No. 35/808.

\section{CONFLICTS OF INTEREST}

The authors declare that there is no conflict of interest.

\section{REFERENCES}

1. McManus DP, Zhang W, Li J, Bartley PB. Echinococcosis. Lancet. 2003;362:1295-304. 


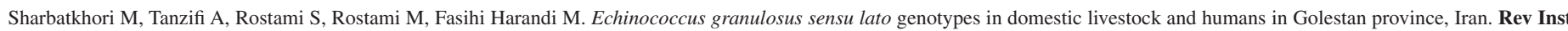
Med Trop Sao Paulo. 2016;58:38.

2. Moro P, Schantz PM. Echinococcosis: a review. Int J Infect Dis. 2009;13:125-33.

3. Eckert J, Gemmell MA, Meslin FX, Pawłowski ZS, editors. WHO/OIE manual on echinococcosis in humans and animals: a public health problem of global concern. Paris: WHO; 2001

4. Fasihi Harandi M, Budke CM, Rostami S. The monetary burden of cystic echinococcosis in Iran. PLoS Negl Trop Dis. 2012;6:e1915.

5. Dalimi A, Motamedi G, Hosseini M, Mohammadian B, Malaki H, Ghamari Z, et al. Echinococcosis/hydatidosis in western Iran. Vet Parasitol. 2002;105:161-71.

6. Rokni M. Echinococcosis/hydatidosis in Iran. Iran J Parasitol. 2009;4:1-16.

7. Sadjjadi SM. Present situation of echinococcosis in the Middle East and Arabic North Africa. Parasitol Int. 2006;55 Suppl:S197-202.

8. McManus DP. Current status of the genetics and molecular taxonomy of Echinococcus species. Parasitology. 2013;140:1617-23.

9. Thompson RC. The taxonomy, phylogeny and transmission of Echinococcus. Exp Parasitol. 2008;119:439-46.

10. Nakao M, McManus DP, Schantz PM, Craig PS, Ito A. A molecular phylogeny of the genus Echinococcus inferred from complete mitochondrial genomes. Parasitology. 2007; 134:713-22.

11. Lavikainen A, Haukisalmi V, Lehtinen MJ, Henttonen H, Oksanen A, Meri S. A phylogeny of members of the family Taeniidae based on the mitochondrial coxl and nadl gene data. Parasitology. 2008;135:1457-67.

12. Saarma U, Jõgisalu I, Moks E, Varcasia A, Lavikainen A, Oksanen A, et al. A novel phylogeny for the genus Echinococcus, based on nuclear data, challenges relationships based on mitochondrial evidence. Parasitology. 2009;136:317-28.

13. Moks E, Jõgisalu I, Valdmann H, Saarma U. First report of Echinococcus granulosus G8 in Eurasia and a reappraisal of the phylogenetic relationships of 'genotypes' G5-G10. Parasitology. 2008;135:647-54.

14. Lymbery AJ, Jenkins EJ, Schurer JM, Thompson RC. Echinococcus canadensis, E. borealis, and E. intermedius. What's in a name. Trends Parasitol. 2015;31:23-9.

15. Hüttner M, Nakao M, Wassermann T, Siefert L, Boomker JD, Dinkel A, et al. Genetic characterization and phylogenetic position of Echinococcus felidis (Cestoda: Taeniidae) from the African lion. Int J Parasitol. 2008;38:861-8.

16. Harandi MF, Hobbs RP, Adams PJ, Mobedi I, Morgan-Ryan UM, Thompson RC. Molecular and morphological characterization of Echinococcus granulosus of human and animal origin in Iran. Parasitology. 2002;125:367-73.

17. Sharbatkhori M, Fasihi Harandi M, Mirhendi H, Hajialilo E, Kia E. Sequence analysis of coxl and nad1 genes in Echinococcus granulosus G3 genotype in camels (Camelus dromedarius) from central Iran. Parasitol Res. 2011;108:521-27.

18. Sharbatkhori M, Mirhendi H, Jex AR, Pangasa A, Campbell BE, Kia EB, et al. Genetic categorization of Echinococcus granulosus from humans and herbivorous hosts in Iran using an integrated mutation scanning-phylogenetic approach. Electrophoresis. 2009;30:2648-55

19. Sharbatkhori M, Kia EB, Fasihi Harandi M, Jalalizand N, Zahabiun F, Mirhendi H. Comparison of five simple methods for DNA extraction from Echinococcus granulosus protoscoleces for PCR amplification of ribosomal DNA. Iran J Parasitol. 2009; 4:54-60.

20. Hajialilo E, Fasihi Harandi M, Sharbatkhori M, Mirhendi H, Rostami S. Genetic characterization of Echinococcus granulosus in camels, cattle and sheep from the south-east of Iran indicates the presence of the G3 genotype. J Helminthol. 2012;86:263-70.
21. Pezeshki A, Akhlaghi L, Sharbatkhori M, Razmjou E, Oormazdi H, Mohebali M, et al. Genotyping of Echinococcus granulosus from domestic animals and humans from Ardabil Province, northwest Iran. J Helminthol. 2013;87:387-91.

22. Pour A, Hosseini S, Shayan P. Comparative genotyping of Echinococcus granulosus infecting buffalo in Iran using coxl gene. Parasitol Res. 2011;108:1229-34.

23. Kamenetzky L, Canova SG, Guarnera EA, Rosenzvit MC. Echinococcus granulosus: DNA extraction from germinal layers allows strain determination in fertile and nonfertile hydatid cysts. Exp Parasitol. 2000;95:122-7.

24. Hall TA. BioEdit: a user-friendly biological sequence alignment editor and analysis program for Windows 95/98/NT. Nucleic Acids Symp Ser. 1999;41:95-8.

25. Page RD. TreeView: an application to display phylogenetic trees on personal computers. Comput Appl Biosci. 1996;12:357-8

26. Bowles J, Blair D, McManus DP. Genetic variants within the genus Echinococcus identified by mitochondrial DNA sequencing. Mol Biochem Parasitol. 1992;54:165 73

27. Bowles J, McManus DP. NADH dehydrogenase 1 gene sequences compared for specie and strains of the genus Echinococcus. Int J Parasitol. 1993;23:969-72.

28. Lavikainen A, Lehtinen MJ, Meri T, Hirvela-Koski V, Meri S. Molecular genetic characterization of the Fennoscandian cervid strain, a new genotypic group (G10) of Echinococcus granulosus. Parasitology. 2003;127:207-15.

29. Bowles J, McManus DP. Molecular variation in Echinococcus. Acta Trop. 1993;53:291 305.

30. Gasser RB, Zhu X, McManus DP. NADH dehydrogenase subunit 1 and cytochrome oxidase subunit I sequences compared for members of the genus Taenia (Cestoda). Int J Parasitol. 1999;29:1965-70.

31. Gholami S, Sosari M, Fakhar M, Sharif M, Daryani A, Hashemi M, et al. Molecular characterization of Echinococcus granulosus from hydatid cysts isolated from human and animals in Golestan province, north of Iran. Iran J Parasitol. 2012;7:8-16.

32. Casulli A, Manfredi MT, La Rosa G, Cerbo ARD, Genchi C, Pozio E. Echinococcus ortleppi and E. granulosus G1, G2 and G3 genotypes in Italian bovines. Vet Parasitol. 2008;155:168-72.

33. Yan N, Nie HM, Jiang ZR, Yang AG, Deng SJ, Guo L, et al. Genetic variability of Echinococcus granulosus from the Tibetan plateau inferred by mitochondrial DNA sequences. Vet Parasitol. 2013;196:179-83.

34. Bardonnet K, Piarroux R, Dia L, Schneegans F, Beurdeley A, Godot V, et al. Combined eco-epidemiological and molecular biology approaches to assess Echinococcus granulosus transmission to humans in Mauritania: occurrence of the camel strain and human cystic echinococcosis. Trans R Soc Trop Med Hyg. 2002;96:383-6.

35. Omer RA, Dinkel A, Romig T, Mackenstedt U, Elnahas AA, Aradaib IE, et al. A molecular survey of cystic echinococcosis in Sudan. Vet Parasitol. 2010;169:340-6.

36. Vural G, Baca AU, Gauci CG, Bagci O, Gicik Y, Lightowlers MW. Variability in the Echinococcus granulosus cytochrome $\mathrm{C}$ oxidase 1 mitochondrial gene sequence from livestock in Turkey and a re-appraisal of the G1-3 genotype cluster. Vet Parasitol. 2008;154:347-50.

37. Espinoza S, Salas AM, Vargas A, Freire V, Diaz E, Sánchez G, et al. Detection of the G3 genotype of Echinococcus granulosus from hydatid cysts of Chilean cattle using coxl and nd1 mitochondrial markers. Parasitol Res. 2014;113:139-47.

38. Umhang G, Richomme C, Boucher JM, Hormaz V, Boué F. Prevalence survey and first molecular characterization of Echinococcus granulosus in France. Parasitol Res. 2013;112:1809-12. 


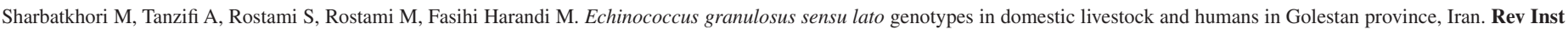
Med Trop Sao Paulo. 2016;58:38.

39. Piccoli L, Bazzocchi C, Brunetti E, Mihailescu P, Bandi C, Mastalier B, et al. Molecular characterization of Echinococcus granulosus in south-eastern Romania: evidence of G1-G3 and G6-G10 complexes in humans. Clin Microbiol Infect. 2013;19:578-82.

40. Singh BB, Sharma JK, Ghatak S, Sharma R, Bal MS, Tuli A, et al. Molecular epidemiology of Echinococcosis from food producing animals in north India. Vet Parasitol. 2012;186:503-6

41. Busi M, Snabel V, De Liberato C, D'Amelio S. Molecular genotyping of Echinococcus granulosus hydatid cysts in Italy reveals the presence of three distinct genotypes. Parassitologia. 2004;46 Suppl 1:164

42. M'rad S, Oudni-M'rad M, Filisetti D, Mekki M, Nouri A, Sayadi T, et al. Molecular identification of Echinococcus granulosus in Tunisia: first record of the Buffalo strain (G3) in human and bovine in the country. Open Vet Sci J. 2010;4:27-30.

43. Kia EB, Rahimi H, Sharbatkhori M, Talebi A, Fasihi Harandi M, Mirhendi H. Genotype identification of human cystic echinococcosis in Isfahan, central Iran. Parasitol Res. 2010;107:757-60.
44. Sadjjadi SM, Mikaeili F, Karamian M, Maraghi S, Sadjjadi FS, Shariat-Torbaghan S, et al. Evidence that the Echinococcus granulosus G6 genotype has an affinity for the brain in humans. Int J Parasitol. 2013;43:875-7.

45. Rostami S, Shariat Torbaghan S, Dabiri S, Babaei Z, Ali Mohammadi M, Sharbatkhori M, et al. Genetic characterization of Echinococcus granulosus from a large number of formalin-fixed, paraffin-embedded tissue samples of human isolates in Iran. Am J Trop Med Hyg. 2015;92:588-94

46. Nakao M, Lavikainen A, Yanagida T, Ito A. Phylogenetic systematics of the genus Echinococcus (Cestoda: Taeniidae). Int J Parasitol. 2013;43:1017-29.

Received: 16 March 2015

Accepted: 19 November 2015 